\title{
A Study of Indoor Air Quality Investigations in B.C Health Authorities Ming-Chen Lee ${ }^{1}$, Helen Heacock ${ }^{2}$, Bobby Sidhu ${ }^{3}$
}

1 Lead Author, B. Tech Student, School of Health Sciences, British Columbia Institute of Technology, 3700 Willingdon Ave, Burnaby, BC V5G 3H2

2, 3 Supervisor, School of Health Sciences, British Columbia Institute of Technology, 3700 Willingdon Ave, Burnaby, BC V5G 3H2

\begin{abstract}
Canadians spend 90 percent of their lifetime indoors and are currently aware that poor indoor air quality (IAQ) can negatively impact human health. If there are any IAQ problems, the Health Authorities will conduct IAQ investigations to respond to the complainants or resolve the conflicts. An online survey to Environmental Health Officers (EHOs) and specialists was used to understand the frequencies that B.C. Health Authorities conduct IAQ investigations, the locations Health Authorities encountered most IAQ queries, the different types of pollutants that IAQ instruments are used for and the preference for instruments chosen. Five common indoor air pollutants, such as mould, volatile organic compounds (VOCs), radon, particulate matters (PMs), CO and CO2, were chosen and the Chi-Square test was used to analyze the data in this study. This study showed that most EHOs had never conducted IAQ investigations since they had worked in the B. C Health Authorities. Mould problems between landlord and tenant were EHOs mostly encountered. The study found that EHOs referred to other agencies or consultants when they received complaints. The data showed that the method of managing IAQ problems was associated with the Health Authorities because few EHOs from Vancouver Coastal Health indicated they had used equipment to conduct IAQ investigations. The mostly encountered location and frequency of conducting radon investigations were significantly associated with the Health Authorities due to an on-going project in Northern Authority. Most EHOs and specialists had shown that they educated public regarding to the information of IAQ instead of monitoring the IAQ pollutants. The results of this study indicate that EHOs did not get involved in IAQ investigations often and also showed that mould problems were the mostly encountered IAQ problems between the Health Authorities. The most important role of EHOs and specialists in this area is to educate public to solve or prevent IAQ problems.

Keywords: Indoor air quality, PMs, CO, CO2, Radon, mould
\end{abstract}

\section{Introduction}

Canadians spend more than $90 \%$ of their lifetime indoors (Health Canada, 2009). Therefore, indoor air quality is important to Canadians. Poor indoor air quality (IAQ) can cause illness and disease, such as heart and respiratory diseases, and low work productivity. Currently there is an increase in awareness of potential health problems; this is related to a decline in indoor air quality. People are likely to complain if they believe that there is poor in IAQ in their workplaces, schools or homes. This is especially true when they feel that the IAQ may affect their health and comfort (Workers' Compensation Board of British Columbia (WCB), 2005).

Environmental Health Officers (EHOs) may get involved when there are any complaints or potential health hazards in buildings, such as schools, hospitals, industries and homes. Conflicts may be caused between bosses and co-workers, or landlords and tenants because of their different positions and perceptions. Hence, site investigations, monitors and standards are important to identify the IAQ problems and provide a resolution to the conflicts.
The initial idea of this study was provided by BCIT Environmental Health Program faculty and instructor, Keith Herle, who was an EHO in Vancouver Coastal Health. This study has two purposes. One is to investigate the IAQ equipment inventory used by the Health Authorities in BC; this enables an understanding of the different types of pollutants that these instruments are used for, and to understand the preferences in instruments chosen. Another purpose of this research is to learn whether the frequencies of conducing IAQ investigations and mostly IAQ encountered locations would be different from one Health Authority to another.

\section{Literature review}

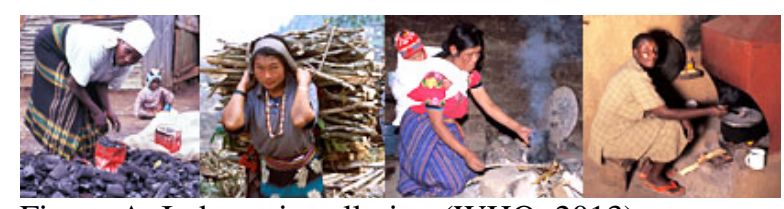

Figure A. Indoor air pollution (WHO, 2013). According to the World Health

Organization (2013), poor IAQ contributes $2.7 \%$ of the global burden of morbidity and mortality. Canadians spend around 90\% of their lifetime indoor, 
such as in homes, schools, as well as recreational and occupational facilities (Health Canada, 2009). Poor IAQ may cause headaches, coughing, sneezing, nausea and asthma (HealthLinkBC, 2012a). In addition, the poor air quality causes huge economic impacts to Canadians, in the order of billions of dollars per year. The economic impacts include low worker productivity and increased healthcare cost due to air pollution treatments (Environmental Canada, 2012). Therefore, maintaining good IAQ is one of the important preventive methods to protect the public from illness and disease. The Health authorities in B.C may get involved in IAQ investigations when there are any existences of a potential health hazard or complaint. Environmental Health Officers (EHOs) will conduct investigations to monitor and identify the problems and pollutant sources. EHOs may recommend and educate the public on poor IAQ prevention and recommend control methods to improve the indoor air quality of the environment and health in a community.

\section{Sources and factors causing indoor air} pollutants

Poor IAQ issues may be caused by building materials, furnishing, or activities within the building occupants, such as insufficient outdoor air intake, inadequate temperature, humidity, lighting, excessive noise, and indoor air pollutants (Canadian Centre for Occupational Health and Safety (CCOHS), 2013). Air pollution is referred to all existences of chemical and biological agents in the air that will cause health threats and damage to the environment by changing

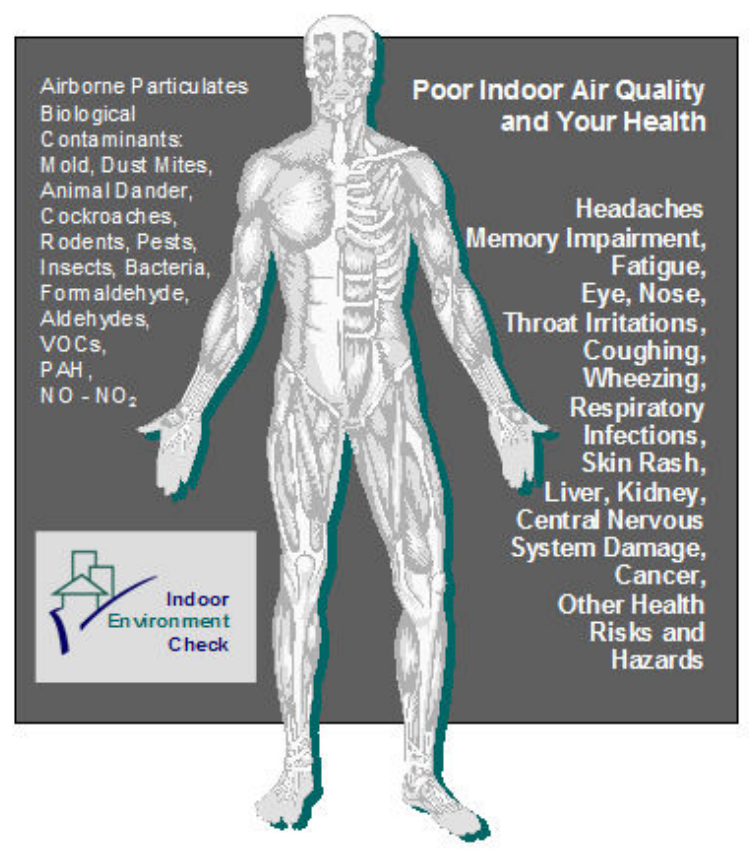

the natural characteristics of the atmosphere (Environmental Canada, 2012).

Common indoor air pollutants are carbon monoxide(CO), carbon dioxide (CO2), volatile organic compounds (VOCs), fine particulates, dust mites, moulds, bacteria and ozone (O3) which are caused by building materials, occupants, furniture, tobacco smoke, cleaners, temperature and moisture (CCOHS, 2013; Environmental Protection Agency (EPA), 2013a). Some air pollutants, such as fine particulate matter, carbon monoxide and nitrogen oxides are caused by burning processes at fireplaces, car exhaust from an attached garage, furnaces and wood heaters (HealthLinkBC, 2012a). Moreover, asbestos can be an IAQ issue in old houses because it has been used as an insulator and fire retardant for many years (HealthLinkBC, 2012a). Radon is another factor that causes IAQ issues due to poorly ventilated basements (Fraser Health, 2011). Lead is also considered as one of the indoor air pollutants in old houses, especially those made before 1960, due to paints and old pipes (Health Canada, 2012).

(1) Public Health Significance

The health that is impacted negatively by indoor air pollutants can be divided into two categories: immediate effects and long-term effects (EPA, 2013a). Immediate effects are caused by short-term exposures. Symptoms that will show up soon after short-term air pollution exposures are asthma, hypersensitivity pneumonitis, and humidifier fever (EPA, 2013a). Longterm effects are caused by long-term repeated indoor air pollution exposures. Health negative impacts which are caused by long-term exposures are heart diseases, respiratory diseases and cancer (EPA, 2013a).

Biological pollutants, such as mould, dust mites, bacteria, viruses and pollen, may cause allergic reactions. And some bacteria and viruses may cause infections, such as Legionnaires' Diseases and Pontiac Fever (HealthLinkBC, 2012c; Health Canada, 2009).

Chemical pollutants include $\mathrm{CO}, \mathrm{NOx}, \mathrm{SO} 2, \mathrm{O} 3$, lead and VOCs. Formaldehyde is one of the common VOCs for IAQ problems (HealthLinkBCb, 2012). It is released from pressed-wood products, such as particleboard, plywood, glues and adhesives, and certain insulation materials (National Cancer Institute (NCI), 2011). Many studies indicate that formaldehyde exposure is associated with several cancers, such as nasopharyngeal cancer and leukemia (NCI, 2011). Health effects by CO include: headaches, dizziness, nausea, angina, or death (EPA, 2013b).

Lead exposure may damage kidney and liver and result in hematopoietic, renal, and hepatic function in children (Khan, Qayyum, Saleem, Ansari \& Khan, 2010). It may also affect the central nervous system

Figure B. Poor indoor air quality and your health (Air Mechanical Inc. 2013). 
Recommended Exposure Limit

Contaminant

and cause children physical and mental development delays, and lower IQ levels (EPA, 2013a). According to Risk Assessment and Indoor Air Quality, Long term radon exposure can cause cancer and SO2 exposure can decrease lung function (Anderson \& Patrick, 1998). The data indicates that long-term particulate matter exposure not only causes respiratory disease, but also is significantly associated with higher cardiovascular morbidity and mortality (Anderson, Thundiyil, \& Stolbach, 2012).

Formaldehyde

Read More About

Formaldehyde

Mould

Read More About

Mould
Maximum exposure limits

[recommended sampling

Long-term [8 hour]: 50

Read the Guideline

$\mu \mathrm{g} / \mathrm{m}^{3}$ (40 ppb)

Short-term [1 hour]: 123

$\mu \mathrm{g} / \mathrm{m}^{3}$ (100 ppb)

Health Canada recommends: 2007

Read the Guideline

To control humidity and

diligently repair any water

damage in residences to

prevent mould growth; and

To clean thoroughly any visible or concealed mould growing in residential buildings.

\begin{tabular}{|c|c|c|}
\hline $\begin{array}{l}\text { Carbon Monoxide } \\
\text { Read the Guideline } \\
\text { Read More About } \\
\text { Carbon Monoxide }\end{array}$ & $\begin{array}{l}\text { Long-term [24 hour]: } \\
11.5 \mathrm{mg} / \mathrm{m}^{3} \text { (10 ppm) } \\
\text { Short-term [1 hour]: } \\
\left.28.6 \mathrm{mg} / \mathrm{m}^{3} \text { ( } 25 \mathrm{ppm}\right)\end{array}$ & 2010 \\
\hline $\begin{array}{l}\text { Nitrogen Dioxide } \\
\text { Read the Guideline }\end{array}$ & $\begin{array}{l}\text { Long-term [24 hour]: } 100 \\
\mu g / m 3 \text { (0.05 ppm) } \\
\text { Short-term [1 hour]: } 480 \\
\mu g / m 3 \text { (0.25 ppm) }\end{array}$ & 1987 \\
\hline $\begin{array}{l}\text { Ozone } \\
\text { Read the Guideline } \\
\text { Read More About } \\
\text { Ozone }\end{array}$ & $\begin{array}{l}\text { Long-term [8 hour]: } 40 \\
\mu g / m 3 \text { (20 ppb) }\end{array}$ & 2010 \\
\hline $\begin{array}{l}\text { Fine Particulate } \\
\text { Matter }\left(\mathrm{PM}_{2.5}\right) \\
\text { Read the Guidance } \\
\underline{\text { Document }}\end{array}$ & $\begin{array}{l}\text { Health Canada recommends: } \\
\text { Indoor levels of } \mathrm{PM}_{2.5} \\
\text { should be kept as low as } \\
\text { possible. } \\
\text { To address the main indoor } \\
\text { sources use a stove top fan } \\
\text { while cooking and do not } \\
\text { allow smoking indoors. }\end{array}$ & 2012 \\
\hline $\begin{array}{l}\text { Toluene } \\
\text { Read the Guideline } \\
\text { Read More About } \\
\text { Toluene }\end{array}$ & $\begin{array}{l}\text { Long-term [24 hour]: } \\
2.3 \mathrm{mg} / \mathrm{m}^{3}(0.6 \mathrm{ppm}) \\
\text { Short-term [8 hour]: } \\
\left.15 \mathrm{mg} / \mathrm{m}^{3} \text { ( } 4.0 \mathrm{ppm}\right)\end{array}$ & 2011 \\
\hline
\end{tabular}

Table 1. Residential indoor air quality guidelines (HC, 2012).

If no illness or cause can be identified but it is directly related to the time that they spent in the building, and victims get better or recover soon after leaving the building, it is often called Sick Building Syndrome (SBS) or Tight Building Syndrome (Joshi, 2008).

(2) Regulatory, Guidelines, Standards Standards in legislation provide a basis for the Health Authorities to enforce indoor air quality in an effort to protect the public from indoor air related illnesses. Examples from the United States are: The Asbestos School Hazard Detection and Control Act of 1980, Lead-Based Paint Poisoning Prevention Act 
of 1971 and the Public Health Cigarette Smoking Act of 1970 etc. (Miller \& Miller, 1998). However, there is no specific legislation for dealing with IAQ issues in Canada, but several organizations have given recommended guidelines and standards for IAQ, such as Health Canada (CCOHS, 2013).

In Canada, concentration levels of some air pollutants in indoor environments have been found to be higher than those in outdoor air. This is because buildings have installed energy saving systems, which reduces the rate of air exchange. A team of experts from the World Health Organization suggested that the Health Authorities make guidelines for concentrations of indoor air pollutants to protect residential health in 1979 (Health Canada, 1987). Therefore, the members of the Federal-Provincial Working group on Indoor Air Quality and Subcommittee on Radiation Surveillance established Residential indoor air quality guidelines which were standardized for air quality in non-industrial indoor environments and were the first guidelines issued in 1987 (Health Canada, 2012).

The guidelines were developed based on assuming exposure for 24 hours per day (Health Canada, 1987). The updated residential indoor air quality guidelines for specific contaminants are displayed in the table 1 (Health Canada, 2012). In addition, the Canadian Mortgage and Housing Corporation (2013) provides guidelines for homeowners about IAQ problems and solutions. This is to educate the public of IAQ problems and corresponding prevention methods. 


\section{(3) Equipment Inventory}

There are many methods to measure indoor air pollutants when the Health Authorities conduct IAQ investigations. In order to identify the problems and resolve the conflicts, accurate measurements are important. Therefore, the selection of methods and equipment are critical factors to get accurate results (Miller \& Miller, 1998).

\section{Particulates:}

The instruments for particulates sampling provided in the IAQ lab at BCIT are PVC filters, SKC Aluminum Respirable Dust Cyclone, Button Sampler (IPM), IOM, Personal Environmental Monitor(PEM), Personal Modular Impactor (PMI), Sioutas Cascade Impactor, Anserson 8 stage nonviable air sampler, Dust Trak, and P Trak (BCIT, 2013). Brooks and Davis (1992) mention that the equipment and methods used for monitoring particulates include PVC filters, Nylon cyclone, Cascade Impactor and Dichotomous Sampler.

\section{Volatile Organic Compounds (VOCs)}

ppB Rae 3000 is used to measure indoor total VOCs in the BCIT indoor air quality lab and Pine Environmental Services company (BCIT, 2013; Pine Environmental Services, LLC., 2009). Other types of equipment used are: gas chromatographs/mass spectrometers (GC/MS) and TenaxGC ${ }^{\circledR}$ (Brooks \& Davis, 1992). Two direct-reading instruments used to monitor Formaldehyde are RKI Instruments Model FP-30 and a PPM Technology Formaldemeter ${ }^{\mathrm{TM}} \mathrm{htV}$ (Centers for Disease Control and Prevention (CDC), 2009).

\section{Carbon Monoxide (CO) \&Carbon Dioxide (CO2)}

The Q trak is used to monitor $\mathrm{CO}$ and $\mathrm{CO} 2$ in IAQ labs at BCIT (2013). Other instruments that are used to monitor CO include, Model 2000 Ecolyzer and Model AG 5100. The instrument used for measuring CO2 is the Gastech Model (Brooks \& Davis, 1992).

\section{Bioaerosols}

Bioaerosols include mould, yeast, and Legionella. The sampling methods used in the IAQ lab at BCIT (2012) are surface swabs, sticky tape, Replicate Organism Direct Agar Contact (RODAC) Plates, Gravitation/ settling Plates, Impingement, Filtration, Impaction, Standard Andersen, Andersen N6, Spore Trap and RCS Centrifugal Air Sampler.

\section{Radon}

The methods of monitoring Radon that Canada Mortgage and Housing Corporation (2007) provided in the guideline are Charcoal Detectors, Passive Alpha-Track Detectors, Active Alpha-Track Detectors, Electret Ion Chamber, and Continuous Monitors.

\section{(4) Reasons for Equipment Selection}

In order to satisfy the market of indoor air quality research and investigation, many instruments are developed, each with a specific purpose. Most instruments are optimum for one purpose but not proper for other purposes (Moffat, 1997). Therefore, the instrument selection becomes very crucial because it may affect the results and decisions. Moffat (1997) provides some general characteristics of instruments that will help investigators, operators or researchers to accomplish their jobs with certain purposes.

a. Ease to use: Some instruments are portable, allowing them to be easy to carry in the field. Some instruments are designed as lighter than others, and some have a function of direct reading rather than analysis required. Some instruments can give the result immediately compared with time-consuming instruments.

b. Quality assurance: Regular maintenance and calibration is required for instruments. Some instruments have self-check features.

c. Based on data output: Different instruments have different ways to display their results. For example, the data can be displayed based on time-averaged, instantaneous readings, sensitivity or selectivity, or compatibility with computer.

d. Cost: Some instruments are chosen because they are less costly than other similar instruments. Some instruments are developed for single use and some are reusable. Therefore, reusable instruments may cost less for a long-term use repeatedly. Some instruments require training prior to usage. Some instruments need to be updated more often than others.

$$
\begin{aligned}
& \text { Most Encountered Indoor Air } \\
& \text { Pollutants }
\end{aligned}
$$

Depending on the various human activities, building ages, or environments in the communities, indoor air pollutants may be different from one another. Some air pollutants may be more crucial to monitoring by the Health Authorities than others. In order to reduce the risk of illness and costs associated, understanding and enhancing prevention methods for those air quality problems that the Health Authorities mostly encounter will be the best pathway to solve the problems.

As awareness of certain illnesses associated with IAQ problems is increasing, public concerns and complaints are also increasing when people feel that poor IAQ may threaten their health. One duty of an EHO is to address complaints and provide accurate monitor results. Therefore, the selection of IAQ 
monitoring instruments is very important to the Health Authorities to respond to poor IAQ complaints and help resolve the conflicts. In addition, to protect the public from illness is a major obligation of Environmental Health Officers. Since Canadians spend most of their lifetime indoors, understanding most indoor air quality problems that the Health Authorities encounter, developing prevention and control methods, and creating guidelines will help individuals and societies enhance their life quality and stay healthy.

\section{Methodology}

\section{Description of Methods}

The target audiences participated in the study by responding to a survey. The survey assisted the study investigator learn the types of equipment that B.C. Health Authorities mainly use for IAQ investigations, the frequencies and locations of IAQ investigations that the Health Authorities conduct, and the indoor air pollutants that the Health Authorities mostly encounter. The data of the study were collected through SurveyMonkey (BCIT, 2013).

SurveyMonkey is an online tool for investigators to create surveys and collect data efficiently, and it allows people from all over the world to participate in the survey through the internet (SurveyMonkey, 2013). The questionnaire was designed for two groups, EHOs and Specialists who are in charge of the IAQ investigations and who currently work in B. C. Health Authorities. The questionnaire was distributed by sending the survey link to the Canadian Institute of Public Health Inspectors (CIPHI) BC Branch president and requesting the president to assist in the distribution process by forwarding it to all EHOs in B. C. and sending via email the invitation letter and the survey link to managers of the Health Authorities to get their agreement and then requesting them to forward to the Specialists who were in charge of IAQ investigations.

The survey mainly included close-ended questions with a few open-ended questions. The purposes of the study and research considerations were stated in the invitation letter and consent form. The invitation letter was sent via email with the survey link to invite to participation. All participants were required to respond to the surveys completely between January $20^{\text {th }}$, 2014 and February $7^{\text {th }}, 2014$. The data of the study were analyzed by NCSS 9 software (Hintze, 2013). The charts and graphs were created by Microsoft Excel 2010 (Microsoft Excel, 2010).

Inclusion and Exclusion Criteria

The inclusion criteria were EHOs who are currently working at the Health Authorities in B.C. In order to learn the types of equipment that are used for particular indoor air pollutants accurately, specialists who are in charge of conducting IAQ investigations in the B.C. Health Authorities were also included in this study. All EHOs and Specialists were invited to participate. 56 EHOs and 5 non-EHOs responded during three week period of data collection.

Occupation positions other than these two and did not get involved IAQ investigations were excluded. Reliability and Validity

Reliability means that measurements are repeatable (Sapsford, 2007). The common method to examine the reliability is to use more than one person and compare their results. If the same or similar results are obtained, then the measurements are reliable (Sapsford, 2007). Internal validity refers to whether the design selected provides accurate measurements of what is supposed to be measured. External validity refers to whether the sample selected gives an accurate representation of the population for the study of purpose (Sapsford, 2007 \& BCIT, 2013).

Participants of the study were asked questions regarding the frequencies and the most encountered locations they have conducted the general IAQ and individual indoor air quality pollutants investigations in a given period of time. The study was reliable due to repeatable questions of this survey.

Moreover, the study was measured by the same questions in the same manner without any investigator bias through online Surveymonkey system. It provided the internal validity of the study. The two populations, general EHOs and employees who are in charge the IAQ investigations in B.C. Health Authorities, were highly correlated in the study. The questionnaire was designed for these two populations. It provided the external validity of the study. In order to improve the reliability and validity, the study performed a pilot study prior to inviting target populations to take part of the study. Pilot Study

The pilot study is used to discover inappropriate questions and improve the reliability, validity and quality of questionnaire before inviting target audiences to participate in the survey. It provides an average time the survey was going to take to complete (Bradburn, Sudman \& Wansink, 2005). The BCIT Environmental Health instructors and students were invited in the pilot study.

\section{Ethical considerations}

According to BCIT policy of Research Ethics for Human Participants (2011), all human participants involved research projects that are carried out by members of the BCIT community, 
including all faculty, staff, and students, must be approved by the BCIT Research Ethics Review Board (REB). The research must comply with Human Rights legislation, such as prohibition of discrimination and confidentiality, and respect the Canadian Charter of Rights and Freedoms (BCIT, 2011).

Therefore, the invitation letter and consent form of this study were sent out with the survey link and assured participants that completing the survey were voluntary. No personal opinions and sensitive private questions were required to be collected in this research. In addition, all questions of the survey were approved by the Environmental Health Instructors of BCIT.

\section{Statistical Analysis}

\section{Type of Data and Descriptive Statistics}

Nominal data were presented in the study

since no numerical values were collected from respondents (BCIT, 2013). Descriptive statistic is defined as any single numerical measure computed from a particular characteristic of the data set (Kleinbaum et. al, 1998). The data that were collected were nominal, so means, medians, ranges and standard deviations were not computed in this study. Microsoft Excel 2010 was used to summarize and present the results of the responses in tables, charts and graphs (2010).

\section{Inferential Statistics}

The Chi- Square was the most appropriate inferential test for this study since it was collected as nominal data (BCIT, 2013). The Chi-Square test was used to identify if there were any associations between the types of equipment used for measuring particular indoor air pollutants, and the most encountered indoor air pollutants, and the Health Authorities in B.C.

In addition, the Chi-Square test was also used to assess whether the frequencies of individual particular pollutants investigations were associated with the Health Authorities. When there are more than $20 \%$ of the expected frequencies less than 5 or there is any frequency less than 2, the P-value of Fisher's Exact test will be used (Dawson \& Trapp, 2001). Otherwise, Pearson's test will be used for data interpretation. If there is any P-value less than 0.05 , the hypothesis will be rejected and will be identified as a significant association between independent and dependent variables.

\section{Results}

74 people participated in the study during three week period of data collection. However, some participants did not complete the questionnaire. In order to keep valuable data and make the study more accurate, the data of respondents who did not answer the first 7 questions, and who responded they had conducted IAQ investigations but did not complete the questionnaire were discarded. The responses of a total of 56 EHOs and 5 non-EHOs from B. C. Health Authorities (HAs) were analyzed in the study.

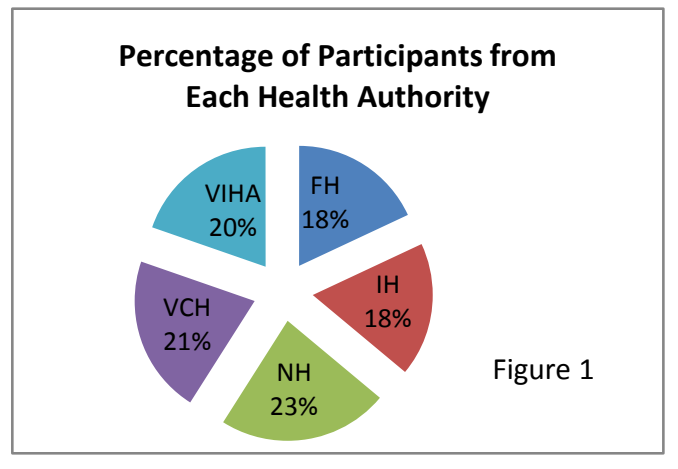

According to the result of data analysis $18 \%$ and 21\% of total participants were from Fraser Health Authority (FH) and Vancouver Coastal Health Authority (VCH); $23 \%$ were from Northern Health Authority (NH), 18\% were from Interior Health Authority and 20\% were from Vancouver Island Coastal Health (VICH) (Figure 1).

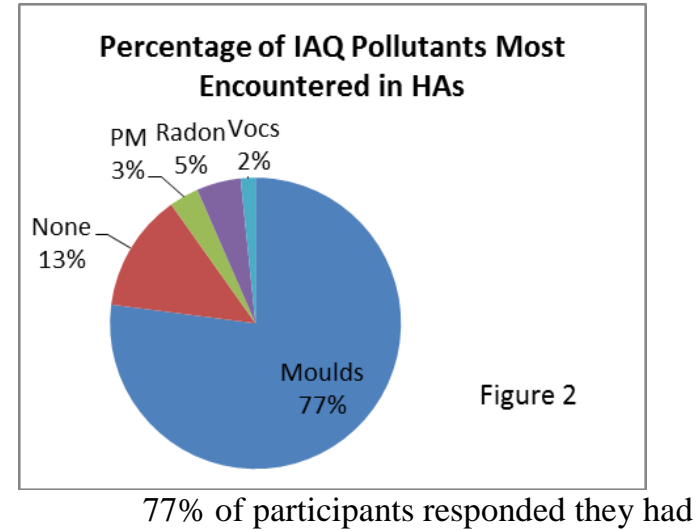

conducted mould investigations most often compared with other common air pollutants (Figure 2). 59\% of total respondents indicated their most encountered location of mould investigations was homes due to landlord and tenants issues, and 32\% of total respondents indicated that their most encountered location was private homes (Figure 3).

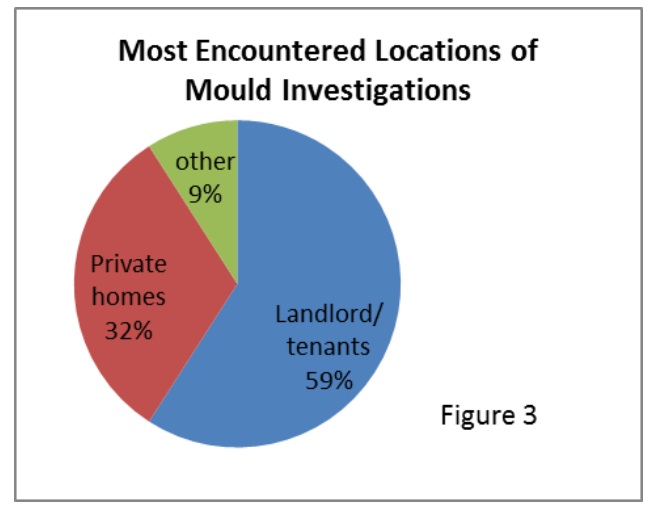


The frequencies that the Health Authorities managed the IAQ problems were defined as how many times that the Health Authorities conducted investigations every half year. $80 \%$ of participants responded that they never or rarely conducted IAQ investigations since they started working in HAs (Figure 4).

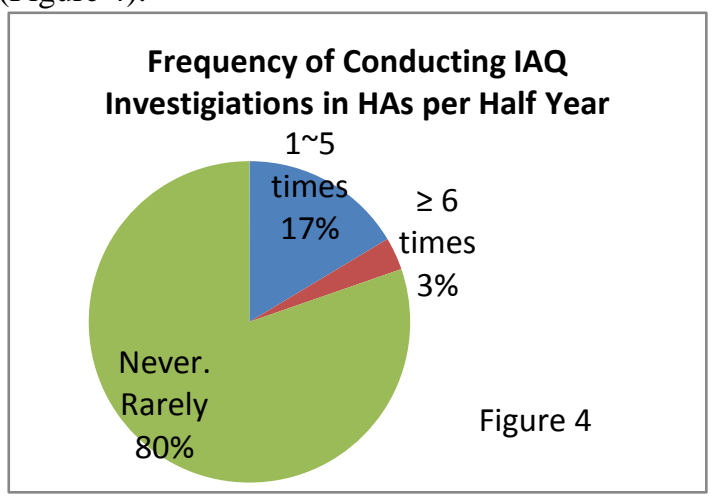

Most respondents indicated that they never conducted these common individual indoor air pollutants investigations. $44 \%$ of respondents who had conducted mould investigations indicated that the methods that they conducted their investigations were by contacting consultants (24\%) and by visual method (16\%) (Figure 5).

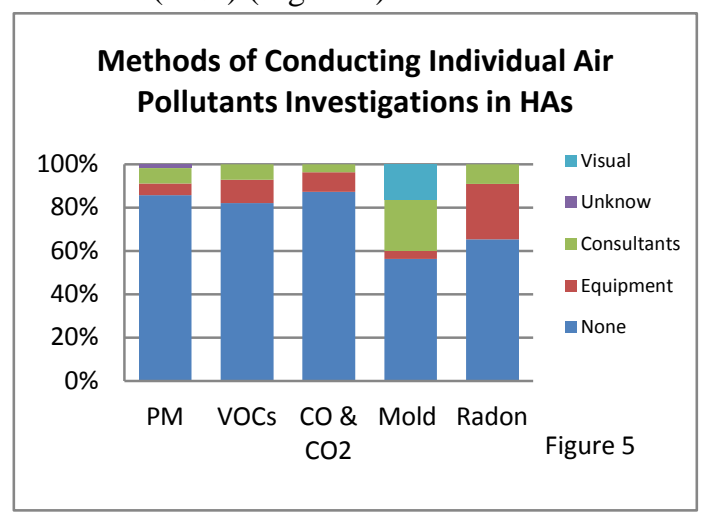

$24 \%$ of respondents indicated the reasons they selected particular methods to conduct their mould investigations were because those were their only options. The reasons of method selection that respondents conducted individual indoor air pollutants investigations included less expensive, easy to use and Quality Assurances (Figure 6).

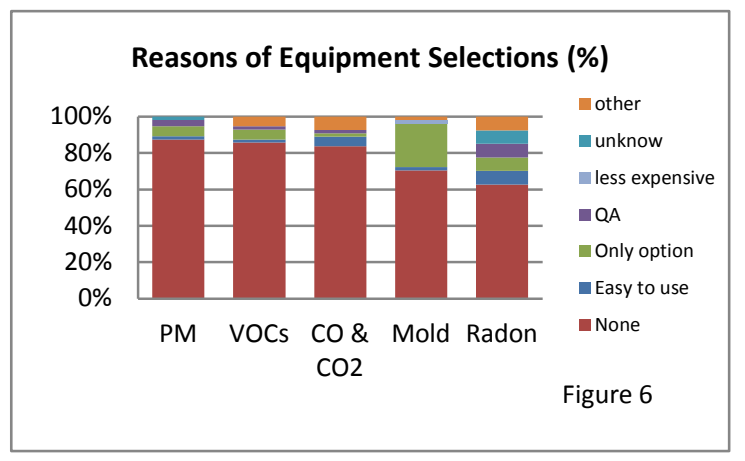

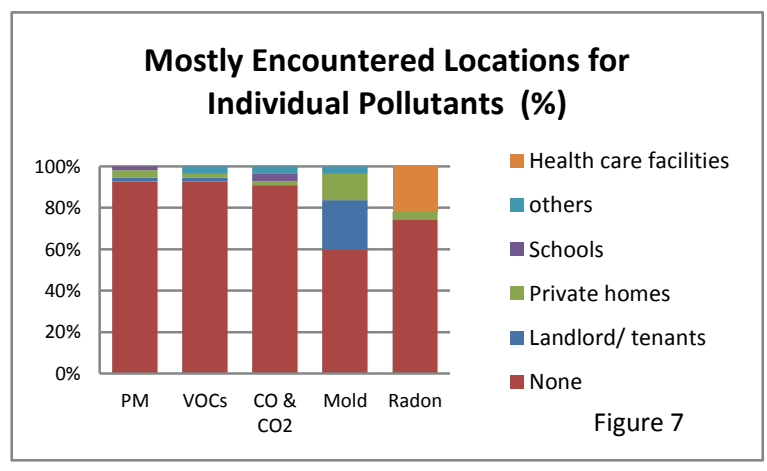

The most encountered location of radon investigations was health care facilities (23\%). Other locations that participants encountered IAQ investigations were commercial buildings and arenas. More than $90 \%$ of respondents reported that they never conducted PMs, VOCs and CO\& CO2 investigations (Figure 7).

\section{Frequency of Conducting Individual Pollutant Investigations (\%)}

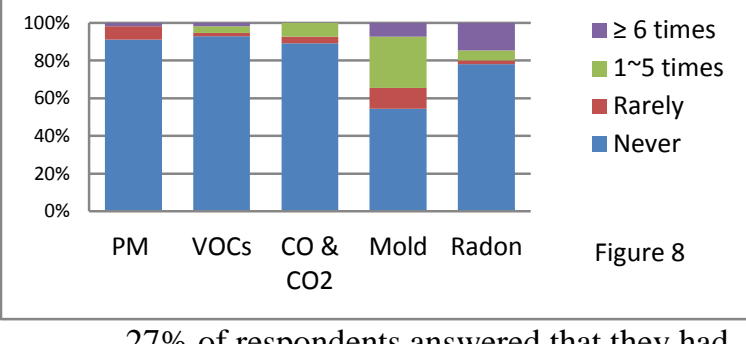
conducted mould investigations between 1 and 5 times per year and $15 \%$ of respondent indicated they had conducted radon investigations more than 6 times per year (Figure 8).

According to the result of the Chi-Square tests (Table 2), the methods of measuring PM, VOCs and $\mathrm{CO} \& \mathrm{CO} 2$ were significantly associated with the Health Authorities (Ho01, Ho04, Ho05: $\mathrm{P}<0.05$ ). This was due to VCH being the only Health Authority to use pieces of equipment to measure PM, VOCs and $\mathrm{CO} \& \mathrm{CO} 2$ during investigations. The study found that the methods used for conducting radon investigations, the most encountered location of radon and the frequency of conducting radon investigations were significantly associated with the Health Authorities, because there was a processing project within approximately 800 daycare facilities in the Northern Health Authority (Ho03, Ho08, Ho13: < 0.05). The result indicated that there were no associations between the method for measuring mould and the Health Authorities (Ho02: $\mathrm{P}=0.058$ ), but the most encountered location of mould and the frequency of conducting mould investigations were significantly associated with the Health Authorities (Ho07, Ho12: $\mathrm{P}<0.05$ ) because most participants 


\begin{tabular}{|c|c|c|c|}
\hline Ho01 & $\begin{array}{l}\text { The methods for } \\
\text { measuring PMs }\end{array}$ & $\mathrm{P}=0.027$ & $\begin{array}{l}\text { Reject } \\
\text { Ho }\end{array}$ \\
\hline Ho02 & $\begin{array}{l}\text { The methods for } \\
\text { measuring Mould }\end{array}$ & $\mathrm{P}=0.058$ & $\begin{array}{l}\text { Accept } \\
\text { Ho }\end{array}$ \\
\hline Ho03 & $\begin{array}{l}\text { The methods for } \\
\text { measuring Radon }\end{array}$ & $\mathrm{P}=0.000$ & $\begin{array}{l}\text { Reject } \\
\text { Ho }\end{array}$ \\
\hline Ho04 & $\begin{array}{l}\text { The methods for } \\
\text { measuring VOCs }\end{array}$ & $\mathrm{P}=0.000$ & $\begin{array}{l}\text { Reject } \\
\text { Ho }\end{array}$ \\
\hline Ho05 & $\begin{array}{l}\text { The methods for } \\
\text { measuring CO \& CO2 }\end{array}$ & $\mathrm{P}=0.003$ & $\begin{array}{l}\text { Reject } \\
\text { Ho }\end{array}$ \\
\hline Ho06 & $\begin{array}{l}\text { Mostly Encountered } \\
\text { locations of PM } \\
\text { investigations }\end{array}$ & $\mathrm{P}=0.545$ & $\begin{array}{l}\text { Accept } \\
\text { Ho }\end{array}$ \\
\hline Ho07 & $\begin{array}{l}\text { Mostly Encountered } \\
\text { locations of Mould } \\
\text { investigations }\end{array}$ & $\mathrm{P}=0.011$ & $\begin{array}{l}\text { Reject } \\
\text { Ho }\end{array}$ \\
\hline Ho08 & $\begin{array}{l}\text { Mostly Encountered } \\
\text { locations of Radon } \\
\text { investigations }\end{array}$ & $\mathrm{P}=0.000$ & $\begin{array}{l}\text { Reject } \\
\text { Ho }\end{array}$ \\
\hline Ho09 & $\begin{array}{l}\text { Mostly Encountered } \\
\text { locations of VOCs } \\
\text { investigations }\end{array}$ & $\mathrm{P}=0.498$ & $\begin{array}{l}\text { Accept } \\
\text { Ho }\end{array}$ \\
\hline Ho10 & $\begin{array}{l}\text { Mostly Encountered } \\
\text { locations of CO \& } \\
\text { CO2 investigations }\end{array}$ & $\mathrm{P}=0.237$ & $\begin{array}{l}\text { Accept } \\
\text { Ho }\end{array}$ \\
\hline Ho11 & $\begin{array}{l}\text { Frequencies of PM } \\
\text { investigations }\end{array}$ & $\mathrm{P}=0.365$ & $\begin{array}{l}\text { Accept } \\
\text { Ho }\end{array}$ \\
\hline Ho12 & $\begin{array}{l}\text { Frequencies of Mould } \\
\text { investigations }\end{array}$ & $\mathrm{P}=0.026$ & $\begin{array}{l}\text { Reject } \\
\text { Ho }\end{array}$ \\
\hline Ho13 & $\begin{array}{l}\text { Frequencies of Radon } \\
\text { investigations }\end{array}$ & $\mathrm{P}=0.005$ & $\begin{array}{l}\text { Reject } \\
\text { Ho }\end{array}$ \\
\hline Ho14 & $\begin{array}{l}\text { Frequencies of VOCs } \\
\text { investigations }\end{array}$ & $\mathrm{P}=0.297$ & $\begin{array}{l}\text { Accept } \\
\text { Ho }\end{array}$ \\
\hline Ho15 & $\begin{array}{l}\text { Frequencies of CO \& } \\
\text { CO2 investigations }\end{array}$ & $\mathrm{P}=0.011$ & $\begin{array}{l}\text { Reject } \\
\text { Ho }\end{array}$ \\
\hline \multicolumn{4}{|c|}{$\begin{array}{l}\text { Table 2. Summary of Hypothesis testing results } \\
\text { ** Ho: variables not associated with the Health } \\
\text { Authorities }\end{array}$} \\
\hline
\end{tabular}

moisture meter, one used scotch tape and microscope, and one used swab to conduct mould investigations. Ten participants used Landauer Radtrak long term monitor to conduct radon tests.

The type I or $\alpha$ error is defined as rejecting Ho when, in reality, Ho should not be rejected (BCIT, 2013). When the limits of P-values were shifted from 0.05 to 0.01 , the results of Ho03 Ho05, Ho08 and Ho13 remained the same since their P-Values were less than 0.01 . Thus, the chances of a type I or $\alpha$ error were low. However, the results of Ho01, Ho07, Ho12 and Ho15 became non-significant associations from significant associations if the limits of the P-values were moved from 0.05 to 0.01 , so there were a potential type I or $\alpha$ error for these rejected null hypotheses.

The type II or $\beta$ error is identified as that when null hypothesis is accepted but the alternative hypothesis is true. It may occur when the sample size is small so the solution for decreasing a chance of the type II or $\beta$ error is to increase the sample size (BCIT, 2013). In the study, when the one side P-Value is between 0.05 and 0.1 , there will be a potential type II or $\beta$ error. According to the data analysis results, the power of Ho02 was less than 0.8 ( $0.05<\mathrm{P}$-value $<$ $0.10)$. It indicated that there was a potential type II or $\beta$ error in this study. Therefore, increasing sample size was required to reduce the chance of a type II or $\beta$ error.

\section{Discussion}

The study revealed that most EHOs had not conducted IAQ investigations since they had worked in the B. C. Health Authorities. If they had conducted IAQ investigations, most of them had conducted mould investigations most often due to conflicts between landlord and tenant or on private homes. Few participants pointed out that they only conducted mould inspection in public buildings, not on private homes. Some EHOs stated that mould was not a health hazard. Few EHOs indicated that New Westminster has a city by-law to manage mould problems between landlords and tenants. Many EHOs pointed out that there was no bylaw to manage mould problems in their municipalities, so they didn't inspect it. Since moisture is root problem of causing mould issues, some EHOs had educated homeowners to fix leaks and clean up to resolve mould problems instead of taking time to monitor and identify mould problems. Some EHOs responded that in order to respond mould complainants, they referred the issues to the Canada Mortgage and Housing Corporation (CMHC) and/or Residential Tenancy Branch.

According to the responses, few EHOs had conducted PM, VOCs and CO\& CO2 investigations in private homes, schools, commercial recreational 
buildings, such as pools, indoor race tracks or arenas. Also, few EHOs from Vancouver Health Authority stated that they used pieces of equipment to monitor PM, VOCs and CO\& CO2 levels. However, due to personal subjective viewpoints, the reasons of the equipment selections were different from one person to another even though they used the same piece of equipment to monitor a particular pollutant. Many EHOs, two Air Quality Specialists and one Public Health Engineer currently worked in Northern Health Authority pointed that they had tested Radon levels by Radtrak long term radon detectors in their healthcare facilities recently due to a 3 year radon detection project in daycares (around 800 daycare facilities). Some EHOs reported that they contacted consultants, other agencies or companies to conduct the assessment when they encountered the IAQ problems.

A member of the Health Authority Air Quality Council (HAAQC) indicated that the Public Health Act and its regulations do not provide any authority for involvement in IAQ within private residential dwellings. A Regional Built Environment Consultant indicated that the Health Authorities do not get involved in this area due to a lack of legislated authority. Instead, EHOs and specialists provided educational materials to the public to promote healthy indoor air quality. Since there were no IAQ standards legislations in Canada, EHOs and specialists do not have any jurisdiction to enforce people to fix the IAQ problems. They only can recommend and educate the public based on the guidelines and standards of indoor air pollutants concentration levels which are provided by Health Canada to promote healthy indoor air quality environment.

\section{Limitations}

Even though there were 74 respondents participated in this study, only 55 respondents completed the questionnaire. In order to keep the valuable information, the data from those who responded "never conducted IAQ investigations" in the general IAQ investigations session were not discarded. However, it affected the validity and reliability of this study because the repeated questions could not be compared to identify whether the data were consistent in those individuals' responses.

The definition of the frequencies was not stated clearly in the questionnaire. Some EHOs might include the frequencies of receiving complaints; some EHOs might think that means the frequencies of conducting on-site investigations only and some EHOs did not know how to respond this type of questions. For example, an EHO clicked the "other" option without providing any number to indicate the frequencies of conducing IAQ investigations and made a comment that he did investigations not as often as site visits. Therefore, the unclear definition of frequencies of conducing IAQ investigations might affect their responses and influence the accuracy of the study as well.

\section{Conclusions}

The study pointed out that most EHOs working in BC Health Authorities had never conducted indoor air quality investigations due to EHOs not having any jurisdiction in their area according to the Public Health Act and its regulation. Most of time, EHOs and specialists provided educational materials or referred to other agencies to respond IAQ complaints and inquires instead of conducting investigations. Northern Health Authority conducted radon investigations more often than other Health Authorities because of an on-going radon monitoring project in daycare facilities. Generally speaking, this study showed that EHOs worked in B. C Health Authorities did not conduct IAQ investigations often. As a role of being EHOs, they provided the public education to promote healthy indoor air quality.

\section{Recommendations}

Canadians spend $90 \%$ of their lifetime in indoor. Having healthy Indoor air quality becomes especially important to protect Canadians from illness and reduce health care costs. However, there is no specific IAQ legislation provided to manage IAQ problems and to resolve landlord and tenant conflicts for the general public. Only few municipalities provide by-laws to regulate mould issues between landlord and tenant. In order to respect the right of having healthy indoor air quality environment to protect residents from illness in B. C., legislation regarding to IAQ should be established.

\section{Future Study}

The study indicated that the mould issue between the landlords and tenants is the most encountered indoor air problem in BC. Investigating the public about the knowledge of mould, and the information of prevention and protection the public health from mould related illness is recommended to the further study.

\section{Acknowledgements}

The author thanks Keith Herle, instructor in the British Columbia Institute of Technology, to provide the idea of the study, the 2013 BC CIPHI Branch president to send the survey link to all BC 
inspectors and all classmates who contacted pilot study and gave recommendations for this study.

\section{References}

Air Mechanical Inc. (2013). Indoor air quality in Minnesota- how is the IAQ in your Ham Lake, Andover, East Bethel, Blaine Home! Retrieved from http://www.replacementairfilters.com/blog/i ndoor-air-quality-in-minnesota-how-is-theiaq-in-your-ham-lake-andover-east-bethelblaine-home/

Anderson, E. L., \& Patrick, D. R. (1998).Introduction to risk assessment. In E. L. Anderson and R. E. Albert (Eds.), Risk assessment and indoor air quality. Retrieved from http://0-

www.crcnetbase.com.innopac.lib.bcit.ca/doi/ pdf/10.1201/9781420048476.ch1

Anderson, J. O., Thundiyil, J. G., \& Stolbach, A. (2012). Cleaning the air: A review of the effects of particulate matter air pollution on human health. Journal of Medical Toxicology, 8(2), 166-175. Retrieved from http://link.springer.com/article/10.1007\%2Fs 13181-011-0203-1\#page-1

British Columbia Institute of Technology (BCIT). (2013, September). ENVH-8400 Research Methods Course Manual. Fall, 2013. Edition.

British Columbia Institute of Technology (BCIT). (2012, January).ENVH 4600 indoor air quality lab manual.

British Columbia Institute of Technology (BCIT). (2011). Research ethics for human participants. Retrieved from http://www.bcit.ca/files/pdf/policies/6500.pd $\mathrm{f}$

Bradburn, N., Sudman, S. \& Wansink, B. (2004). Asking questions: Asking and recording Open-Ended and Closed-Ended Questions. San Francisco: John Wiley \& Sons, Inc.

Brooks, B. O. \& Davis, W. F. (1992). Understanding indoor air quality. Florida: CRC Press.

Canadian Centre for Occupational Health and Safety. (2013). Indoor air quality - general. Retrieved from http://www.ccohs.ca/oshanswers/chemicals/i aq_intro.html

Canada Mortgage and Housing Corporation. (2013). Moisture and air: Householder's guide problems and remedies. Retrieved from http://www.cmhcschl.gc.ca/en/co/grho/moaiprre/

Canada Mortgage and Housing Corporation. (2007). Radon: A guide for Canadian homeowners.
Retrieved from http://www.bubbletech.ca/pdfs/61945.pdf

Centers for Disease Control and Prevention. (2009). Short-term monitoring of formaldehyde: Comparison of two direct-reading instruments to a laboratory-based method. Retrieved from http://www.cdc.gov/nceh/ehhe/trailerstudy/p dfs/formaldehyde-instrument-report_33105b.pdf

Dawson, B. \& Trapp, R. G. (2001). Basic \& clinical biostatistics ( $3^{\text {rd }}$ ed.). New York, NY: The McGraw-Hill Companies, Inc.

Fraser Health. (2011). Indoor air quality. Retrieved from http://www.fraserhealth.ca/your_environmen t/air-quality/indoor/

Health Canada. (1987). Exposure guidelines for residential indoor air quality. Retrieved from: http://www.hc-sc.gc.ca/ewhsemt/pubs/air/exposure-exposition/indexeng.php

Health Canada. (2009). Environmental and workplace health: Indoor air quality and health. Retrieved from http://www.hcsc.gc.ca/ewh-semt/air/in/qual/index-eng.php

Health Canada. (2012). Exposure guidelines for residential indoor air quality. Retrieved from http://www.hc-sc.gc.ca/ewhsemt/pubs/air/exposure-exposition/indexeng.php

HealthLinkBC. (2012a). Indoor air quality. Retrieved from

http://www.healthlinkbc.ca/healthfiles/hfile6 5 a.stm

HealthLinkBC. (2012b). Indoor air quality: Volatile organic compounds. Retrieved from http://www.healthlinkbc.ca/healthfiles/hfile6 5 d.stm

HealthLinkBC. (2012c). Indoor air quality: mould and other biological contaminants. Retrieved from http://www.healthlinkbc.ca/healthfiles/hfile6 5b.stm

Hintze, J. (2013). NCSS 9. NCSS, LLC. Kaysville, Utah, USA. Retrieved from www.ncss.com

Joshi, S. M. (2008). The sick building syndromes. Indian Journal of Occupational and Environmental Medicine, 12(2), 61-64 Retrieved from http://www.ncbi.nlm.nih.gov/pmc/articles/P MC2796751/

Khan, D. A., Qayyum, S., Saleem, S. S., Ansari, W. M. \& Khan, D. A. (2010). Lead exposure and its adverse health effects among occupational worker's children. Journal of 
Toxicology and Industrial Health, 26(8), 497-504.

Kleinbaum, D. G.,Kupper, L. L., Muller, K. E. \& Nizam, A. (1998). Applied regression analysis and other multivariable methods ( $3^{\text {rd }}$. ed.). Pacific Grove: Brooks/Cole Publishing Company.

Microsoft ${ }^{\circledR}$ Corporation. (2010). Microsoft ${ }^{\circledR}$ Office Home and Student 2010: Excel 2010.

Miller, E. W., \& Miller, R. M. (1998). Indoor pollution. California: ABC-CLIO, Inc.

Moffat D. W. (1997). Handbook of indoor air quality management. New Jersey: Prentice Hall, Inc.

National Cancer Institute (NCI). (2011).

Formaldehyde and cancer risk. Retrieved from http://www.cancer.gov/cancertopics/factshee t/Risk/formaldehyde

Pine Environmental Services, LLC. (2009). RAE systems MiniRAE 3000 PID. Retrieved from http://pineenvironmental.com/product/instruments/rae minirae_3000/

World Health Organization. (2013). Indoor air pollution. Retrieved from http://www.who.int/indoorair/en/

Workers' Compensation Board of British Columbia. (2005). Indoor air quality: A guide for building owners, managers, and occupants. Retrieved from http://www.worksafebc.com/publications/he alth_and_safety/by_topic/assets/pdf/indoor_ air_bk89.pdf

Sapsford, R. (2007). Survey research $\left(2^{\text {nd }}\right.$ ed). London: SAGE Publication Inc.

SurveyMonkey® (2013). SurveyMonkey. Retrieved

from https://www.surveymonkey.com/

United States Environmental Protection Agency. (2013a). An introduction to indoor air quality. Retrieved from http://www.epa.gov/iaq/ia-intro.html

United States Environmental Protection Agency. (2013b). An Introduction to indoor air quality: Carbon monoxide. Retrieved from http://www.epa.gov/iaq/co.html 